\title{
Cancer mortality among electric utility workers exposed to polychlorinated biphenyls
}

\author{
Department of \\ Epidemiology, \\ University of North \\ Carolina at Chapel \\ Hill, Chapel Hill, NC, \\ USA \\ D Loomis \\ A P Schenck \\ E Gregory \\ D A Savitz \\ Department of Air \\ Quality, Wageningen \\ Agricultural \\ University, \\ Wageningen, The \\ Netherlands \\ D Loomis \\ Department of \\ Preventive Medicine, \\ University of Kentucky \\ Medical Center, \\ Lexington KY, USA \\ $S$ R Browning \\ Correspondence to: \\ Dr Dana Loomis \\ Department of \\ Epidemiology, CB 7400 \\ School of Public Health \\ UNC-CH, Chapel Hill, NC \\ 27599-7400 USA.
}

\section{Dana Loomis, Steven R Browning, Anna P Schenck, Eileen Gregory, David A Savitz}

\begin{abstract}
Objectives-To assess whether excess mortality from cancer, malignant melanoma of the skin, and cancers of the brain and liver in particular, is associated with long term occupational exposure to polychlorinated biphenyls (PCBs).

Methods-An epidemiological study of mortality was conducted among 138905 men employed for at least six months between 1950 and 1986 at five electrical power companies in the United States. Exposures were assessed by panels composed of workers, hygienists, and managers at each company, who considered tasks performed by workers in 28 job categories and estimated weekly exposures in hours for each job. Poisson regression was used to examine mortality in relation to exposure to electrical insulating fluids containing PCBs, controlling for demographic and occupational factors.
\end{abstract}

Results-Neither all cause nor total cancer mortality was related to cumulative exposure to PCB insulating fluids. Mortality from malignant melanoma increased with exposure; rate ratios (RRs) relative to unexposed men for melanoma were 1.23 (95\% confidence interval $(95 \%$ CI) 0.56 to 2.52$), 1.71(0.68$ to 4.28$)$ and 1.93 (0.52 to 7.14 ) for men with $<2000$, $>2000-10000$, and $>10000$ hours of cumulative exposure to PCB insulating fluids, respectively, without consideration of latency. Lagging exposure by 20 years yielded RRs of $1.29(0.76$ to 2.18$), 2.56(1.09$ to 5.97), and $4.81(1.49$ to 15.50$)$ for the same exposure levels. Mortality from brain cancer was modestly increased among men with $<2000$ hours (RR 1.61, 95\% CI 0.86 to 3.01) and $>2000-10000$ hours exposure (RR 1.79, 95\% CI 0.81 to 3.95), but there were no deaths from brain cancer among the most highly exposed men. A lag of five years yielded slightly increased RRs. Mortality from liver cancer was not associated with exposure to PCB insulating fluids.

Conclusions-This study was larger and provided more detailed information on exposure than past investigations of workers exposed to PCBs. The results suggest that PCBs cause cancer, with malignant melanoma being of particular concern in this industry.

(Occup Environ Med 1997;54:720-728)
Keywords: polychlorinated biphenyls; malignant melanoma; electric utility workers

Polychlorinated biphenyls (PCBs) entered commercial use around 1930 and were produced in large quantities for use as insulating fluids in electrical transformers, capacitors, and switches until health and environmental concerns led to restrictions on their production and use in the $1970 \mathrm{~s}^{1-5}$ PCBs produce various adverse health effects in humans, ${ }^{1}$ notably disorders of the skin and liver, which were described among occupationally exposed workers as early as the $1930 \mathrm{~s},{ }^{167}$ as well as cancer in animals. ${ }^{1}$

Despite actions to limit exposure to PCBs, the question of whether chronic, low level exposures are carcinogenic to humans has not been resolved. ${ }^{8}$ Most people have measurable accumulations of PCBs in their adipose tissue and may receive further exposure from persistent environmental sources. ${ }^{39}$ Workers exposed to PCBs now or in the past are likely to have acquired far greater cumulative exposures, and electrical workers, in particular, continue to be exposed to PCBs through servicing old devices that still contain PCB insulating oils, removing and destroying PCB insulating fluids, and decommissioning contaminated equipment.

Electrical power company workers constitute the largest group with past and present exposure to PCBs. ${ }^{10}$ Cancer risks among these workers have not previously been examined in relation to exposures to PCBs. However, utility workers have measurable PCB uptake reflected by serum concentrations. ${ }^{11} 12$ Industrial hygiene data indicate that skin contact is the primary route of exposure for electrical workers. ${ }^{113}$ Such contact may come about directly among those who work with PCB insulating oils or, indirectly, through leakage, explosions, and contamination of air, work areas, tools, and clothing. ${ }^{11}$

The most informative epidemiological data on cancer among populations exposed to PCBs come from retrospective mortality studies of six cohorts of capacitor and transformer manufacturing workers in the United States, Italy, and Canada. ${ }^{14-20}$ Findings on specific cancer sites are inconsistent, with excess mortality from all cancers combined reported in several studies, ${ }^{14-16} 1820$ but excesses of an array of specific cancers reported in one or two studies each. The results of the four most informative studies ${ }^{16-19}$ collectively suggest the possibility of excess risks from cancers of the liver and brain and malignant melanoma, and a smaller effect on mortality from all cancers 
combined. These results receive additional support from reports of increased mortality from total cancer in one other, much smaller, study of capacitor manufacturing workers in Sweden, ${ }^{21}$ excess liver cancer in one other reasonably large cohort study that lacked information on exposures, ${ }^{14}{ }^{15}$ and a considerable increase in mortality from malignant melanoma in a small, early study. ${ }^{22}$

To advance knowledge about the carcinogenicity of long term exposure to PCBs, we analysed cancer mortality among a historical cohort of 139000 electric utility workers in the United States. We considered mortality from all cancers combined, and from brain cancer, liver cancer, and malignant melanoma. These cancers were selected based on the epidemiological literature, with consideration given to industrial hygiene studies indicating dermal exposures $^{11}{ }^{13}$ and carcinogenicity studies in animals, ${ }^{18}$ as well as the number of cases available.

\section{Methods}

COHORT DEFINITION AND ENUMERATION

The assembly and follow up of the cohort and the assessment of exposures were undertaken primarily to investigate the relation of cancer mortality to exposure to magnetic fields. The methods of enumerating and following up the cohort have been described previously. ${ }^{23}$ Briefly, men employed full time at any of five electric utility companies in the United States at any time between 1 January 1950 and 31 December 1986 and with a total of at least six months of continuous employment were eligible. Women were excluded because they rarely worked in jobs with the exposures of interest. The cohort was enumerated through personnel records, with a complete history of jobs held at the company collected for each worker. A total of 138905 eligible men were included in the analysis. Occupational titles (over 25000 in all) for jobs that were similar with respect to primary tasks, work environments, and responsibility were collapsed into 28 occupational categories. $^{24}$

MORTALITY FOLLOW UP AND CLASSIFICATION OF CAUSES OF DEATH

Vital status on 31 December 1988 was sought for all 76934 workers who had retired or left employment. For men who were still employed on 1 January 1979 or later, we relied on the National Death Index, whereas workers who had left employment earlier were followed up with several data sources, including Social Security Administration Death Benefit records, Health Care Financing Administration files, driving records, credit bureaux, and state offices of vital records. ${ }^{23}$ Through this effort, 55423 cohort members were classified as alive at the end of the study, 20733 were classified as dead, and only 778 were lost.

Death certificates were obtained from state vital records offices for $20068(96.8 \%)$ men identified as dead. The underlying cause of death was coded by trained nosologists according to the ninth revision of the international classification of diseases (ICD-9). ${ }^{25}$ The 665 men for whom death certificates were not found were included only in analyses of total mortality. For analyses of mortality from specific cancers within the cohort, liver cancer was defined by ICD-9 codes 155.0 and 155.2155.9 for liver cancer excluding bile ducts, brain cancer by ICD-9 code 191 for primary cancers of the brain, and malignant melanoma by ICD-9 code 172 , for malignant melanoma of the skin.

ASSESSMENT OF EXPOSURE TO PCBS

During the study period, PCBs were used in insulating fluids in transformers, capacitors, and switches. Capacitor grade insulating fluids were pure PCBs, whereas transformer grade insulating fluids were typically mixtures of about $70 \%$ PCBs and $30 \%$ chlorinated benzene solvents. Other transformers used mineral oil insulating fluids, but these often became contaminated with PCBs during maintenance operations. None of the five companies in the study had historical records of PCB exposures during the study period. In the absence of direct information, estimates from expert panels and walk through industrial hygiene surveys were used to assess exposures to PCBs for each company. ${ }^{26}$

A separate expert panel was constituted for each of the participating companies. The members were industrial hygienists, safety personnel, managers, and long term workers who were familiar with their company's operations over extended periods. They were asked to assess the potential for exposure to PCBs, solvents, wood preservatives, and sunlight for each occupational category in each decade 195088. Panelists were individually given instructions and a form on which to record their assessments. No information was provided about identifiable individual workers or their vital status. The members' assignments of exposure were discussed in meetings of the panel chaired by one of us (SRB), and the consensus of the group concerning each occupational category and decade was used as the estimate of exposure for their company.

The exposure assessment for PCBs focused on workers' contact with insulating fluids containing that agent, whether in pure form or blended with other constituents. The panels provided information that indicated, for each occupational category and decade, the frequency (in times a week) and duration (in hours) of exposure to insulating fluids that contained PBCs during the average working week. The panels' assessments were used to construct company and calendar time specific job exposure matrices. ${ }^{27}$ For an individual worker, exposure to PCB insulating fluids was estimated cumulatively, by summing the product of the frequency and duration of exposure over a work history, yielding exposure estimates with units of cumulative hours of exposure.

Information from the panels was supplemented by data collected through site visits and walk through industrial hygiene surveys. A certified industrial hygienist and at least one other member of the study staff visited selected facilities at each company. Work processes were 


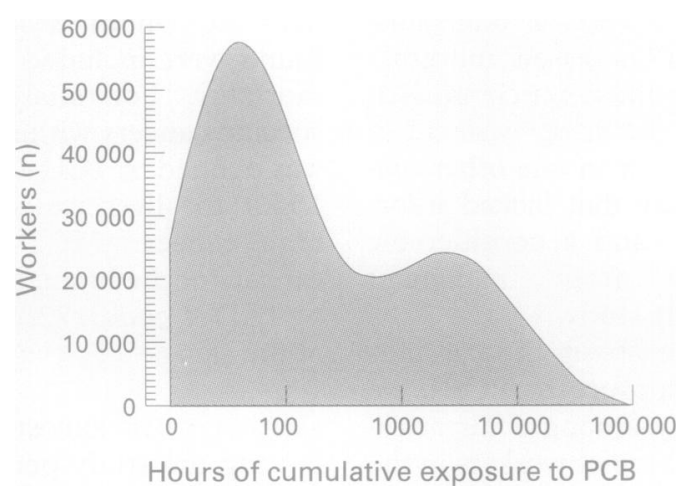

Distribution of individual cumulative exposure to $P C B$ in electric utility workers.

observed, and workers and other personnel were informally interviewed. The first hand knowledge gained from these surveys was used primarily to interpret the panels' assessments of exposure.

As well as the company and decade specific estimates of average weekly exposure to PCB insulating fluids, each occupational category was classified according to whether or not workers employed in it were potentially exposed to PCB insulating fluids. The following categories were potentially exposed to PCB mechanics, electricians, linemen, cable splicers, substation operators, riggers, materials handlers, and labourers. These assessments were based on a synthesis of the results of the expert panel assessment, combined with information obtained from the walk through industrial hygiene surveys.

\section{EXPOSURES TO OTHER AGENTS}

The expert panels also assessed occupational exposures to solvents, wood preservatives, and sunlight. The data for solvents indicated the typical frequency and duration of weekly exposures. Solvents were used as thinners, degreasers, cleaners, and lubricants. They included 1,1,1-trichloroethane, acetone, carbon tetrachloride, and Varsol.

The assessments of exposures to wood preservatives and sunlight were less detailed. A job was classified as potentially exposed to wood preservatives if the panels indicated that workers in it handled or climbed poles and timbers treated with any wood preserving agent in a given decade and company. Creosote, pentachlorophenol, and chromate copper arsenate were the principal preservatives used during the study period. For sunlight, the panels classified each job as involving primarily indoor or primarily outdoor work. Information on occupational exposure to sunlight was collected only at the three largest companies, so exposures at the two smaller ones were estimated.

Exposure to magnetic fields is associated with mortality from brain cancer in the cohort and was thus considered a potential confounder for that disease. Cumulative exposure to magnetic fields was estimated from personal measurements of randomly selected workers. ${ }^{28}$ Exposures to magnetic fields in the period two to 10 years before observation are most strongly associated with brain cancer in this cohort, ${ }^{23}$ so we considered cumulative exposure to magnetic fields within that time window to control confounding most effectively.

\section{STATISTICAL ANALYSIS}

The mortality experience of the cohort was compared with that of the United States population with a standard, modified life table approach $^{29}$ to produce standardised mortality ratios (SMRs), indirectly adjusted for age, calendar year, and race. For these comparisons, underlying causes of death were grouped in standard categories used by the United States National Institute for Occupational Safety and Health. ${ }^{29}$ In all analyses, men who were lost to follow up were treated as lost from the time they were last known to be alive, usually when they left employment.

Exposure-response relations for total mortality, all cancers, brain cancer, liver cancer, and malignant melanoma were examined with Poisson regression to generate adjusted mortality rate ratios (RRs) and approximate $95 \%$ confidence intervals (95\% CIs). ${ }^{30}$ The generalised linear interactive modelling (GLIM) program ${ }^{31}$ was used for model fitting. Exact methods were used to compute upper confidence bounds for exposure categories with no deaths. ${ }^{32}$

Cancer risk was considered in relation to the duration of employment in occupational categories with potential exposure to PCB insulating fluids by contrasting the mortality of men with experience in one or more exposed job with that of men who never worked in any exposed job. We first modelled relations between mortality and cumulative exposure to PCB insulating oils treating them as an ordered categorical variable. Plots of the cumulative exposure distribution (figure) were examined to find cut off points for categories of exposure to PCB insulating fluids. We retained a control group with 0 hours of exposure to PCB oil and aggregated workers to form exposed groups with >0-2000 hours, >2000-10 000 hours, and $>10000$ hours of exposure. To assess the possible dependence of the results on this choice of cut off points and to examine the linearity of trends, we also conducted analyses with a continuous quantitative variable in place of categories for cumulative hours of exposure to PCB insulating fluids. The values of this variable were assigned from the midpoints of deciles of the exposure distribution among all men who had died, because Poisson regression models are fitted to grouped, rather than individual, data.

To account for cancer latent periods, cumulative exposure estimates were lagged to discount recent exposures. Although biological latent periods are generally not known, they can be approximated through trial and error by examining an array of different lag intervals. ${ }^{33}$ The interval that maximises the cancer $R R$ should be the best estimate of the average latent period because cancer incidence peaks around the average time elapsed since first exposure,$^{34}$ which corresponds to the latent period on the population level. Because 
Table 1 Standardised mortality ratios for cause specfic mortality of United States electric utility workers, 1950-88, relative to United States men, estimated by modified lifetable approach

\begin{tabular}{|c|c|c|c|c|}
\hline Cause of death (ICD-9 codes) & $\begin{array}{l}\text { Observed } \\
\text { deaths }\end{array}$ & $\begin{array}{l}\text { Expected } \\
\text { deaths }\end{array}$ & $S M R$ & $95 \% \mathrm{CI} t$ \\
\hline All deaths & 20733 & 26779.5 & 0.77 & 0.76 to 0.78 \\
\hline All cancers $(140-239)^{\star}$ & 4833 & 5615.1 & 0.86 & 0.84 to 0.89 \\
\hline MN of buccal cavity and pharynx (142-149) & 110 & 162.2 & 0.68 & 0.56 to 0.82 \\
\hline $\mathrm{MN}$ of stomach $(151)$ & 175 & 260.5 & 0.67 & 0.58 to 0.78 \\
\hline $\mathrm{MN}$ of intestine excluding rectum (152-153) & 468 & 503.4 & 0.93 & 0.85 to 1.02 \\
\hline $\mathrm{MN}$ of rectum (154) & 109 & 138.7 & 0.79 & 0.65 to 0.95 \\
\hline MN of liver, biliary passages, and gall bladder $(155.0,155.1,156)$ & 67 & 91.8 & 0.73 & 0.57 to 0.93 \\
\hline MN of liver, not specified (155.2) & 35 & 44.3 & 0.79 & 0.55 to 1.10 \\
\hline $\mathrm{MN}$ of pancreas (157) & 243 & 289.2 & 0.84 & 0.74 to 0.95 \\
\hline $\mathrm{MN}$ of trachea, bronchus, and lung (162) & 1692 & 1859.5 & 0.91 & 0.87 to 0.95 \\
\hline $\mathrm{MN}$ of breast (174-175) & 6 & 7.5 & 0.80 & 0.29 to 1.74 \\
\hline $\mathrm{MN}$ of prostate (185) & 387 & 432.7 & 0.89 & 0.81 to 0.99 \\
\hline MN of kidney (189.0-189.2) & 101 & 132.5 & 0.76 & 0.62 to 0.93 \\
\hline $\mathrm{MN}$ of urinary organs $(188,189.3-189.9)$ & 129 & 151.9 & 0.85 & 0.71 to 1.01 \\
\hline $\mathrm{MN}$ of skin $(172-173)$ & 116 & 111.9 & 1.04 & 0.86 to 1.24 \\
\hline MN of brain and nervous system (191-192) & 151 & 158.4 & 0.95 & 0.81 to 1.12 \\
\hline Neoplasms of lymphatic and haematopoietic tissue & 439 & 532.4 & 0.82 & 0.75 to 0.91 \\
\hline Lymphosarcoma and reticulosarcoma (200) & 69 & 89.6 & 0.77 & 0.60 to 0.97 \\
\hline Hodgkin's disease (201) & 30 & 55.9 & 0.54 & 0.36 to 0.77 \\
\hline Leukaemia and aleukaemia (204-208) & 164 & 217.0 & 0.76 & 0.64 to 0.88 \\
\hline Other lymphatic neoplasms $(202-203)$ & 176 & 169.9 & 1.04 & 0.89 to 1.20 \\
\hline Benign neoplasms of the eye, brain (224-225) & 6 & 10.9 & 0.55 & 0.20 to 1.20 \\
\hline Neoplasms of unspecified nature of eye, brain $(237.5-238.9,239.6,239.7)$ & 39 & 33.3 & 1.17 & 0.83 to 1.60 \\
\hline Diabetes mellitus (250) & 219 & 389.2 & 0.56 & 0.49 to 0.64 \\
\hline Diseases of the heart (390-429) & 7768 & 10209.1 & 0.76 & 0.74 to 0.78 \\
\hline Cerebrovascular disease $(430-438)$ & 1244 & 1695.1 & 0.73 & 0.69 to 0.78 \\
\hline Diseases of the respiratory system (460-519) & 1178 & 1716.8 & 0.69 & 0.65 to 0.73 \\
\hline Cirrhosis of the liver (571) & 410 & 648.4 & 0.63 & 0.57 to 0.70 \\
\hline Transportation accidents (E800-848, E929.0-929.1) & 810 & 1105.8 & 0.73 & 0.68 to 0.78 \\
\hline Accidental falls (E880-888, E929.3) & 141 & 190.8 & 0.74 & 0.62 to 0.87 \\
\hline Suicide (E950-959) & 536 & 661.3 & 0.81 & 0.74 to 0.88 \\
\hline Homicide (E960-978) & 175 & 418.1 & 0.42 & 0.36 to 0.49 \\
\hline
\end{tabular}

$\mathrm{MN}=$ malignant neoplasm; ${ }^{\star}$ Causes of death grouped by National Institute for Occupational Safety and Health category (Steenland et al, 1990); † SMR, standardised mortalilty ratio adjusted for age, race, and calendar year.

random error may compromise the ability to identify latent periods empirically, ${ }^{35}$ we also assessed model fit to help evaluate differences in lags.

All RRs in internal analyses were adjusted for known predictors of occupational mortality, including age and calendar decade at risk, race, social class, and current work status. Race had two categories-white and non-white-and social class was represented by the job at hire, assigned to one of four categories (upper white collar, lower white collar, upper blue collar, and lower blue collar). All other variables were time dependent. Work status (active or inactive with a two year lag) was included to help control for the healthy worker effect. ${ }^{36}$ Continuous age variables based on the midpoints of five-year groups were used for compatibility with known relations between age and mortality, as well as for statistical efficiency. A log linear (Gompertz) age function was used for total mortality, and a power function relating the log of age with the log of risk was used for cancer. This model has been shown to fit age specific cancer rates in humans and is compatible with mathematical models of carcinogenesis. ${ }^{37}$ However, we obtained similar results for PCBs with models with nominal variables for fiveyear age groups, which required fewer assumptions.

Occupational exposures to other agents were also considered as potential confounders, but were only retained in the model if they changed the estimated RR for exposure to PCB insulating fluids by at least $10 \%$. The occupational agents considered were solvents and magnetic fields in analyses of brain cancer, solvents in analyses of liver cancer, and solvents, wood preservatives, and sunlight in analyses of melanoma. Exposure to sunlight was measured cumulatively, by a categorical variable with levels of $0,1-9,10-19$, and $\geqslant 20$ years, and cumulative exposure to magnetic fields in the previous two to 10 years was categorised as in our previous study of that agent. ${ }^{23}$ Variables for all other chemical exposures were binary indicators for ever versus never having been exposed.

\section{Results}

MORTALITY PATTERNS

The period of follow up included 2.66 million person-years of experience, during which there were 20733 deaths (table 1). The cohort was predominantly white $(>90 \%)$, and relatively young, with the patterns of all cause mortality expected of an advantaged industrial workforce. ${ }^{23}$ The favourable SMR of 0.77 for all causes of death was largely attributable to low mortality from cardiovascular diseases and cancer (table 1). Among specific cancers, the observed number of deaths was near expectation only for brain and skin cancers and a group of miscellaneous lymphatic neoplasms (table 1).

EMPLOYMENT IN POTENTIALLY EXPOSED JOBS

Total cancer mortality was not related to the total duration of employment in jobs with potential exposures to dielectric fluids containing PCBs, or to employment as an electrician, labourer, and material handler (table 2). However, RRs of the order of 1.2 to 1.3 were found among men with long employment as mechanics, linemen, or cable splicers. 
Table 2 Relative risk of cancer mortality by duration of employment in jobs with potential exposure to PCBs, estimated by Poisson regression: United States electric power utility study, 1950-88

\begin{tabular}{|c|c|c|c|c|c|c|c|c|c|c|c|c|c|}
\hline \multirow{2}{*}{$\begin{array}{l}\text { Duration of } \\
\text { employment } \\
\text { (y) }\end{array}$} & \multicolumn{3}{|c|}{ Total cancer } & \multirow{2}{*}{$\begin{array}{l}\text { Duration of } \\
\text { employment } \\
\text { (y) }\end{array}$} & \multicolumn{3}{|c|}{ Brain cancer } & \multicolumn{3}{|c|}{ Liver cancer } & \multicolumn{3}{|c|}{ Malignant melanoma } \\
\hline & Deaths & $R R^{*} t$ & $(95 \% C I)^{*}$ & & Deaths & $R R$ & $95 \% C I$ & Deaths & $R R$ & $95 \% C I$ & Deaths & $R R$ & $95 \% C I$ \\
\hline \multicolumn{14}{|c|}{ Any exposed occupational category: } \\
\hline $0 \ddagger$ & 2297 & 1.00 & - & 0.00 & 68 & 1.00 & - & 27 & 1.00 & - & 45 & 1.00 & - \\
\hline$>0-5$ & 916 & 1.06 & 0.93 to 1.16 & $>0-5$ & 32 & 1.30 & 0.76 to 2.22 & 13 & 1.08 & 0.51 to 2.27 & 25 & 1.25 & 0.59 to 2.62 \\
\hline$>5-10$ & 454 & 1.03 & 0.93 to 1.15 & $>5-10$ & 15 & 1.36 & 0.72 to 2.55 & 5 & 0.80 & 0.30 to 2.18 & 9 & 1.10 & 0.46 to 2.66 \\
\hline$>10-20$ & 601 & 1.12 & 1.01 to 1.23 & $>10-20$ & 17 & 1.29 & 0.70 to 2.36 & 13 & 1.75 & 0.85 to 3.62 & 11 & 1.38 & 0.58 to 3.28 \\
\hline$>20$ & 565 & 1.08 & 0.97 to 1.19 & $>20$ & 12 & 1.09 & 0.55 to 2.16 & 5 & 0.68 & 0.25 to 1.85 & 8 & 1.55 & 0.58 to 4.16 \\
\hline \multicolumn{14}{|l|}{ Mechanics: } \\
\hline 0.00 & 2297 & 1.00 & - & 0.00 & 68 & 1.00 & - & 27 & 1.00 & - & 45 & 1.00 & - \\
\hline$>0-5$ & 210 & 1.25 & 1.08 to 1.45 & $>0-10$ & 11 & 1.84 & 0.90 to 3.78 & 6 & 1.77 & 0.68 to 4.58 & 8 & 2.57 & 1.06 to 6.20 \\
\hline$>5-10$ & 92 & 1.16 & 0.94 to 1.44 & $>10$ & 0.00 & 0.00 & 0.00 to 1.62 & 0.00 & 0.00 & 0.00 to 3.34 & 3 & 3.16 & $\begin{array}{l}0.92 \text { to } \\
10.85\end{array}$ \\
\hline$>10-20$ & 91 & 1.29 & 1.04 to 1.59 & & & & & & & & & & \\
\hline$>20$ & 32 & 1.35 & 0.95 to 1.92 & & & & & & & & & & \\
\hline \multicolumn{14}{|l|}{ Electricians: } \\
\hline 0.00 & 2297 & 1.00 & - & 0.00 & 68 & 1.00 & - & 27 & 1.00 & - & 45 & 1.00 & - \\
\hline$>0-5$ & 135 & 1.17 & 0.98 to 1.40 & $>0-10$ & 13 & 2.55 & 1.30 to 4.99 & 1 & 0.40 & 0.05 to 2.91 & 2 & 0.61 & 0.13 to 2.90 \\
\hline$>5-10$ & 69 & 1.09 & 0.86 to 1.39 & $>10$ & 3 & 0.83 & 0.25 to 2.76 & 3 & 1.21 & 0.35 to 4.15 & 1 & 0.49 & 0.06 to 3.87 \\
\hline$>10-20$ & 93 & 1.06 & 0.86 to 1.31 & & & & & & & & & & \\
\hline$>20$ & 86 & 1.12 & 0.90 to 1.40 & & & & & & & & & & \\
\hline \multicolumn{14}{|c|}{ Linemen and cable splicers: } \\
\hline 0.00 & 2297 & 1.00 & - & 0.00 & 68 & 1.00 & - & 27 & 1.00 & - & 45 & 1.00 & - \\
\hline$>0-5$ & 200 & 1.01 & 0.87 to 1.17 & $>0-10$ & 13 & 1.26 & 0.64 to 2.50 & 5 & 1.00 & 0.36 to 2.76 & 11 & 1.14 & 0.14 to 8.96 \\
\hline$>5-10$ & 148 & 1.26 & 1.06 to 1.49 & $>10$ & 15 & 1.72 & 0.90 to 3.25 & 6 & 1.22 & 0.48 to 3.10 & 4 & 0.52 & 0.05 to 5.46 \\
\hline$>10-20$ & 185 & 1.11 & 0.95 to 1.29 & & & & & & & & & & \\
\hline$>20$ & 208 & 1.18 & 1.01 to 1.36 & & & & & & & & & & \\
\hline \multicolumn{14}{|c|}{ Labourers and material handlers: } \\
\hline 0.00 & 2297 & 1.00 & - & 0.00 & 106 & 1.00 & - & 27 & 1.00 & - & 45 & 1.00 & - \\
\hline$>0-5$ & 798 & 1.10 & 0.99 to 1.22 & $>0-10$ & 34 & 1.61 & 0.85 to 3.05 & 17 & 1.81 & 0.82 to 4.03 & 21 & 0.75 & 0.21 to 2.65 \\
\hline$>5-10$ & 196 & 0.93 & 0.79 to 1.09 & $>10$ & 4 & 0.83 & 0.26 to 2.62 & 4 & 1.19 & 0.36 to 3.96 & 5 & 1.24 & 0.27 to 5.63 \\
\hline$>10-20$ & 218 & 1.08 & 0.93 to 1.27 & & & & & & & & & & \\
\hline$>20$ & 131 & 0.98 & 0.80 to 1.18 & & & & & & & & & & \\
\hline
\end{tabular}

^All RRs adjusted for age, calendar time, race, social class, and active work status, with additional adjustment as follows. Brain cancer, magnetic fields and solvents liver cancer, solvents; malignant melanoma, occupational sunlight and wood preservatives. tControl group for all RRs, 0 years in any exposed occupational category.

Relative to men who had never held jobs with potential exposure to PCB insulating fluids, mortality from brain cancer was increased among men with up to 20 years experience in potentially exposed jobs, but not among men with longer employment (table 2). A similar pattern of excess mortality restricted to men with relatively short employment prevailed among mechanics, electricians, labourers and material handlers. Among linemen and cable splicers, however, there was a suggestion of risk increasing with longer employment.

There was little evidence of excess liver cancer among men who had worked in jobs with potential exposure to PCB insulating fluids, considered as a group (table 2). Among labourers and material handlers, there was some indication of higher risk, but again primarily among those with shorter tenure.

By contrast, mortality rates from malignant melanoma were increased among men with any experience in potentially exposed jobs (table 2). Among mechanics, mortality from malignant melanoma increased with longer employment (table 2), but the numbers of deaths among men employed for more than 10 years were small. There was no clear indication of excess mortality from malignant melanoma among workers who had held other specific jobs with potential exposures to PCBs (table 2).

CUMULATTVE EXPOSURE TO PCBS

Estimated cumulative exposure to $\mathrm{PCB}$ insulating fluids was unrelated to total mortality, with RRs relative to unexposed men of 0.95 , 1.04 , and 0.89 for men with $>0-2000$,
$>2000-10000$ and >10 000 hours of cumulative exposure, respectively. The large size and long follow up time yielded narrow $95 \%$ CIs, but all included unity. Total cancer mortality was not related to exposure to PCB insulating fluids (table 3 ).

Mortality from brain cancer was increased among men with 2000-10 000 hours of exposure to PCB insulating fluids, but there were no deaths among workers exposed for $>10000$ hours (table 3). The RRs of 1.6-1.8 found in the intermediate exposure categories when all exposure in a worker's career was considered (no lag) rose to about 2.0 with cumulative exposure lagged by five years, but lags of 10 and 20 years diminished or eliminated the association (table 3). The model with a five-year lag also fitted the data somewhat better than those with other lags, although the fit of all the models was good.

Without controlling for exposure to solvents (data not shown), there seemed to be a slight excess of deaths from liver cancer among men with intermediate levels of exposure to PCB insulating oils, which was strongest with a lag of five years (RR 1.18, 1.33, and 1.10 for men with >0-2000, >2000-10 000, and >10 000 hours respectively). However, having worked in a job with exposure to solvents was strongly associated with mortality from liver cancer ( $R R$ $5.77,95 \%$ CI 2.18 to 15.35 with no lag), giving the potential for strong confounding. When solvent exposure was included in the model as a potential confounder, mortality from liver cancer was no longer associated with exposure to PCB insulating oils. The RRs for all 
Table 3 Cancer mortality by lag interval in relation to estimated cumulative PCB exposure, estimated by Poisson regression: United States electric power utility study, 1950-88

\begin{tabular}{|c|c|c|c|c|c|c|c|c|c|c|c|c|}
\hline \multirow{2}{*}{$\begin{array}{l}\text { Cumulative exposure } \\
\text { (h) }\end{array}$} & \multicolumn{3}{|c|}{ Total cancer } & \multicolumn{3}{|c|}{ Brain cancer } & \multicolumn{3}{|c|}{ Liver cancer } & \multicolumn{3}{|c|}{ Malignant melanoma } \\
\hline & Deaths & $R R^{*}$ & $95 \% C I^{*}$ & Deaths & $R R$ & $95 \% C I$ & Deaths & $R R$ & $95 \% C I$ & Deaths & $R R$ & $95 \% C I$ \\
\hline \multicolumn{13}{|c|}{ Total career exposure: } \\
\hline 0.00 & 778 & 1.00 & - & 15 & 1.00 & - & 11 & 1.00 & - & 10 & 1.00 & - \\
\hline$>0-2000$ & 3320 & 0.95 & 0.87 to 1.04 & 110 & 1.61 & 0.86 to 3.01 & 42 & 0.55 & 0.23 to 1.21 & 73 & 1.23 & 0.59 to 2.52 \\
\hline$>2000-10000$ & 552 & 1.04 & 0.92 to 1.17 & 19 & 1.79 & 0.81 to 3.95 & 8 & 0.63 & 0.23 to 1.74 & 12 & 1.71 & 0.68 to 7.14 \\
\hline$>10000$ & 183 & 0.99 & 0.84 to 1.17 & 0.00 & 0.00 & 0.00 to 0.67 & 2 & 0.45 & 0.09 to 2.18 & 3 & 1.93 & 0.52 to 7.14 \\
\hline \multicolumn{13}{|l|}{5 y lag: } \\
\hline 0.00 & 826 & 1.00 & - & 17 & 1.00 & - & 11 & 1.00 & - & 12 & 1.00 & - \\
\hline$>0-2000$ & 3316 & 1.04 & 0.95 to 1.12 & 112 & 2.01 & 1.12 to 3.63 & 43 & 0.70 & 0.32 to 1.50 & 72 & 1.61 & 0.83 to 3.13 \\
\hline$>2000-10000$ & 524 & 1.14 & 1.01 to 1.28 & 15 & 1.98 & 0.89 to 4.43 & 7 & 0.72 & 0.25 to 2.05 & 11 & 2.26 & 0.93 to 5.51 \\
\hline$>10000$ & 167 & 1.07 & 0.90 to 1.27 & 0.00 & 0.00 & 0.00 to 0.82 & 2 & 0.60 & 0.13 to 2.83 & 3 & 3.24 & 0.97 to 10.9 \\
\hline \multicolumn{13}{|l|}{10 y lag: } \\
\hline 0.00 & 1048 & 1.00 & - & 32 & 1.00 & - & 16 & 1.00 & - & 26 & 1.00 & - \\
\hline$>0-2000$ & 3184 & 1.03 & 0.95 to 1.11 & 102 & 1.44 & 0.89 to 2.30 & 39 & 0.58 & 0.30 to 1.13 & 62 & 1.06 & 0.62 to 1.79 \\
\hline$>2000-10000$ & 463 & 1.12 & 1.00 to 1.26 & 10 & 1.14 & 0.52 to 2.53 & 6 & 0.62 & 0.22 to 1.70 & 8 & 1.28 & 0.54 to 3.04 \\
\hline$>10000$ & 138 & 1.02 & 0.85 to 1.23 & 0.00 & 0.00 & 0.00 to 1.11 & 2 & 0.60 & 0.13 to 2.71 & 2 & 3.86 & 1.54 to 9.66 \\
\hline \multicolumn{13}{|l|}{20 y lag: } \\
\hline 0.00 & 1816 & 1.00 & - & 73 & 1.00 & - & 30 & 1.00 & - & 47 & 1.00 & - \\
\hline$>0-2000$ & 2605 & 1.04 & 0.97 to 1.11 & 66 & 1.04 & 0.69 to 1.56 & 29 & 0.50 & 0.28 to 0.90 & 42 & 1.29 & 0.76 to 2.17 \\
\hline$>2000-10000$ & 331 & 1.18 & 1.05 to 1.34 & 5 & 0.73 & 0.28 to 1.90 & 3 & 0.42 & 0.12 to 1.43 & 8 & 2.56 & 1.09 to 5.97 \\
\hline$>10000$ & 81 & 1.01 & 0.81 to 1.28 & 0.00 & 0.00 & 0.00 to 2.57 & 1 & 0.44 & 0.06 to 3.02 & 1 & 4.81 & 1.49 to 15.1 \\
\hline
\end{tabular}

* All RRs adjusted for age, calendar time, race, social class, and active work status, with additional adjustment as follows. Brain cancer, magnetic fields and solvents; liver cancer, solvents; malignant melanoma, occupational sunlight and wood preservatives.

exposure categories were less than unity regardless of the lag period (table 3 ).

Mortality from malignant melanoma increased monotonically with increasing cumulative exposure to PCB insulating fluids (table 3). Simultaneous adjustment for occupational exposure to sunlight and wood preservatives altered the $R R$ by a factor of $>20 \%$, so these variables were retained in the model. Adjustment for solvents had essentially no effect and was omitted. Mortality from melanoma was quantitatively associated with exposure to PCB insulating fluids regardless of which lag interval was considered, but increased with longer lags, from about twice the expected rate among the most highly exposed men when latency was not considered, to almost five times that expected (RR 4.81, 95\% CI 1.49 to 15.51 ) with a lag of 20 years. Varying the lag had little effect on model fit, which was adequate for all models. However, there was only one death in the highest exposure category after imposing the 20 year lag.

Because the numbers of deaths were small among men with $>10000$ hours of exposure, the analyses for specific cancer sites were repeated with the upper two exposure categories collapsed to form two exposed groups with $>0-2000$ and $>2000$ cumulative hours. The results were qualitatively similar to those obtained with three exposure groups. The RRs for brain cancer among men with $>2000$ hours of exposure to PCB insulating fluids were 1.38 (95\% CI 0.63 to 3.25$)$ and $1.55(95 \%$ CI 0.70 to 3.43) for lags of zero and five years, respectively. The RRs for malignant melanoma in this new exposure category were 1.74 (95\% CI 0.71 to 4.22 ) and 2.52 (95\% CI 1.09 to 5.81 ) for lags of zero and 20 years.

When a continuous variable was used to express cumulative exposure to PCB insulating fluids, there was little or no indication of a linear trend in relative risk with increasing exposure for total cancer, or for brain or liver cancer, regardless of the lag interval (table 4). Relative risks for malignant melanoma were slightly higher, but the trend was weak for lags of $0-10$ years. With a 20 year lag, however, the relative risk of melanoma increased 5\%/2000 hours of exposure (table 4).

\section{Discussion}

Neither all cause nor all cancer mortality was related to cumulative exposure to electrical insulating fluids containing polychlorinated biphenyls or to employment in potentially exposed jobs. Mortality from liver cancer was also unrelated to cumulative exposure to PCB insulating fluids, to total employment in potentially exposed jobs, and to most individual exposed jobs.

Table 4 Trends in cancer relative risk by lag interval with respect to quantative change in cumulative PCB exposure: United States electric power utility study, 1950-88

\begin{tabular}{|c|c|c|c|c|c|c|c|}
\hline \multicolumn{2}{|c|}{ Total cancer } & \multicolumn{2}{|c|}{ Brain cancer } & \multicolumn{2}{|c|}{ Liver cancer } & \multicolumn{2}{|c|}{ Malignant melanoma } \\
\hline$R R t$ & $95 \% C I$ & $R R$ & $95 \% C I$ & $R R$ & $95 \% C I$ & $R R$ & $95 \% C I$ \\
\hline \multicolumn{8}{|c|}{ Total career exposure: } \\
\hline $\begin{array}{c}1.000 \\
5 \text { y lag: }\end{array}$ & 1.000 to 1.000 & 1.005 & 0.978 to 1.033 & 1.010 & 0.976 to 1.046 & 1.020 & 0.990 to 1.051 \\
\hline 1.000 & 1.000 to 1.000 & 0.993 & 0.961 to 1.027 & 1.011 & 0.975 to 1.049 & 1.018 & 0.984 to 1.054 \\
\hline 10 y lag: & & & & & & & \\
\hline 1.000 & 1.000 to 1.000 & 0.985 & 0.948 to 1.023 & 1.007 & 0.968 to 1.047 & 1.017 & 0.980 to 1.055 \\
\hline 1.000 & 1.000 to 1.000 & 0.993 & 0.948 to 1.040 & 0.981 & 0.924 to 1.042 & 1.050 & 1.010 to 1.092 \\
\hline
\end{tabular}

† All RRs for 2000 hours of PCB exposure, and estimated by Poisson regression with a quantitative exposure term, adjusting for age, calendar time, race, social class, and active work status, with additional adjustment as follows. Brain cancer, magnetic fields and solvents; liver cancer, solvents; malignant melanoma, occupational sunlight and wood preservatives. 
Excess mortality from brain cancer was found for short term workers in some exposed jobs and for workers with intermediate, but not high, cumulative exposures. However, the lack of either strong or consistent associations of brain cancer with exposure to PCB insulating fluids, coupled with a tendency for mortality rates to decline with longer employment and greater exposure, weaken support for a causal relation with this disease.

In contrast, mortality from malignant melanoma of the skin was increased among men with the longest employment in jobs potentially exposed to PCB insulating fluids, and increased steadily with cumulative exposure to PCB insulating fluids. Lagging cumulative exposure by successively longer intervals produced higher RRs, of the order of two to five, among the most highly exposed workers. Confidence in some of these results is, however, limited by the small numbers of men in the higher exposure groups, particularly with long lags.

Repetition of the analysis with a continuous variable and a categorical variable with different cut off points for the level of exposure to PCB insulating fluids produced qualitatively similar results. This similarity suggests that the findings are relatively robust, despite quantitative differences related to units and assumptions about the shape of the exposure-response relation.

Our results suggest that exposure to electrical insulating fluids, the main constituent of which is PCBs may cause malignant melanoma of the skin. A causal relation is biologically plausible in the light of the known carcinogenicity of PCBs to animals ${ }^{2-5}$ and observations that skin contact with insulating oils from electrical equipment is the principal route of exposure for workers who maintain oil filled electrical equipment. ${ }^{11}$

We found that mortality from melanoma was highest among mechanics, who were potentially exposed to PCBs when servicing oil filled transformers, circuit breakers, and switches. Tasks with potential dermal exposure included changing bushes on oil filled equipment, handling and replacing failed capacitors, and inspecting, sampling, testing, and filtering dielectric oils and cleaning up oil spills.

Our best estimate of the latent interval for melanoma suggests the greatest risk may occur two or more decades after exposure, consistent with PCBs having an effect early in carcinogenesis. Such a latent interval would be similar to Nicholson's estimate from toxicokinetic models that indicate that risk may be highest 15 or more years after first exposure. ${ }^{10}$ However, the increased rate of melanoma with the longest lag might also be explained by secular changes in the qualitative or quantitative aspects of exposure to PCBs. Our assessments indicated that the frequency and duration of exposure to $P C B$ insulating fluids declined substantially after the 1970 s, when PCBs began to be withdrawn from use. One study of blood concentrations of PCBs among California electric utility workers in the $1980 \mathrm{~s}^{38}$ supports the panels' judgement that exposures were low by that time. Secular change in the formulation of PCBs is another possible explanation for these patterns. Although we did not formally assess the composition of PCBs used in the industry, regulation and routine replacement probably began to reduce the average chlorination level of PCBs from the 1970s onward. However, existing materials remained in use until they were replaced through clean up programmes or normal maintenance, so any change in the qualitative nature of PCB exposures is likely to have been gradual.

Few other epidemiological studies provide relevant information about malignant melanoma among workers exposed to PCBs. Excess risk was noted in two studies which did provide data, with $R R s$ of the order of 2.0-4.0. ${ }^{19}{ }^{22}$ However, neither study was large enough for a detailed examination of latency or exposure-response relations, as the larger had only eight cases. ${ }^{19}$

The epidemiological literature is inconsistent on the relation of brain cancer and PCBs. RRs from 2.0-5.0 relative to external control populations have been reported in two studies. ${ }^{18}{ }^{19}$ In analyses internal to one cohort, mortality from brain cancer increased with exposure score but not with duration of employment in exposed jobs. ${ }^{19}$ Another study, in which a semiquantitative exposure score based on an expert assessment was used, reported no excess deaths from brain cancer among directly exposed transformer assembly workers. ${ }^{17}$

The absence of any independent association between exposure to PCB insulating oils and mortality from liver cancer was unequivocal in our study, but results from other epidemiological investigations are inconsistent with each other and with findings from the laboratory. Greenland et al reported that, after controlling for solvents, there was a roughly twofold increase in mortality from liver cancer among transformer assembly workers exposed to PCBs. ${ }^{17}$ Risk ratios of the order of two to three relative to national populations were reported in two other studies, ${ }^{14}{ }^{16}$ one of which excluded workers exposed to solvents. ${ }^{16}$ No excess of liver cancer was found in three other cohorts, however. ${ }^{18-20}$

Polychlorinated biphenyls have been classified as probable human carcinogens, ${ }^{8}$ but epidemiological studies provide little evidence of highly specific associations between exposures to PCBs and cancer at particular sites. As well as the cancers we studied, increased risk of cancers of the gastrointestinal tract, ${ }^{14-16}$ cancer of the pancreas, ${ }^{1520}$ leukaemias, ${ }^{15}$ and lymphomas ${ }^{17}$ have been found. These diverse findings contrast with the results of animal experiments, in which excess liver cancer has been found consistently. ${ }^{18}$ Lack of specificity is not necessarily evidence against causality. ${ }^{39}$ Different routes of exposure and differences in metabolism between species may account for differences between animal and human studies, and differences in population composition may contribute to divergent results in human studies. The level and qualitative nature of exposures to $\mathrm{PCBs}$ may also vary due to differ- 
ences in chemical formulation or transformations during use. ${ }^{40}$

Among the principal limitations of this study are several aspects of exposure assessment. Our evaluation of PCBs and other chemicals was indirect and based on judgement. Comparisons of assessments by experts with objective measurements indicate that these two approaches can give comparable results, ${ }^{41}{ }^{42}$ and for PCBs, biological monitoring of other groups of workers performing similar tasks confirms the potential for significant exposure. ${ }^{11} 12$ Nevertheless, confidence in our results would be enhanced if more direct measures of exposure were available.

We were unable to directly assess the use of personal protective equipment. Unstructured interviews with workers indicated that gloves and long sleeves were sometimes worn for protection, but may not have been effective. ${ }^{43}$ Also, we could not separate the effects of pure PCBs from those of other consitituents of dielectric fluids in actual use. Other constituents of these fluids include mineral oils and chlorinated benzene solvents that were added to PCBs in producing some types of insulating fluids, as well as polychlorinated dibenzodioxins and dibenzofurans that may have been present as contaminants or products of pyrolysis. For this study, we had no information on the concentrations or chemistry of these other substances or about workers' exposures to them independent of PCBs. Epidemiological evidence that these other agents cause malignant melanoma is relatively limited. ${ }^{44}$

The quality of our information on exposure to sunlight, a potentially important confounder, is of some concern. We estimated data for occupational sunlight exposures at two companies. However, the three companies for which sunlight exposures were directly assessed were the largest ones that we studied, contributing $82 \%$ of total person years and $91 \%$ of deaths from melanoma. Extreme differences in the patterns of exposure at the two smaller companies versus the three larger ones would be required to alter the relations found. We also lacked information about exposure to sunlight during leisure time. A strong association of melanoma with recreational exposure to sun could distort our results, if that exposure were differential by level of exposure to PCBs. Other studies suggest that melanoma from recreational exposure to sun is positively associated with social class-such that nonmanual workers are at highest risk. ${ }^{45}$ We adjusted for social class to help control for the influence of such exposures. However, it is likely that the complexity of class and its relation to exposure to sun during leisure time were imperfectly specified by the data available to us, so the control of confounding may have been incomplete. ${ }^{46}$

The use of data on cancer mortality, rather than incidence, is another limitation of the study design. Cancer subtypes could not be examined in detail because the coding system used on death certificates does not distinguish cell types for brain or liver cancer, and the anatomical site of most malignant melanomas is unspecified. Also, diagnostic information on death certificates may be inaccurate. It was not feasible to obtain hospital pathology records for cancer cases; however, a large study of the quality of cancer data on United States death certificates suggests that both false positive and false negative indications of melanoma and brain cancer are likely to be relatively rare on death certificates when compared with hospital pathology reports. ${ }^{47}$ The quality of death certificate data was notably lower for liver cancer, so the potential for error involving this disease may be of greater concern.

The number of cancer deaths also remained a limitation of this study, although it was larger than previous epidemiological studies of workers exposed to PCBs. The RRs for specific cancers among highly exposed and long term workers must be interpreted with care, particularly when long lag intervals were specified, because the numbers of deaths in such groups were generally small.

Despite some important limitations, this study advances knowledge about the health effects of PCBs. In particular, the combination of large size and detailed exposure data provide greater ability to examine details of exposureresponse relations and temporal aspects of risk, relative to earlier efforts. Also, we controlled for several potentially confounding occupational exposures not considered in most previous studies, as well as for known demographic determinants of risk.

In total, our study adds weight to the epidemiological evidence suggesting that polychlorinated biphenyls are carcinogenic to humans, with malignant melanoma being of greatest concern. These findings support past actions taken to reduce exposures to PCBs and suggest that efforts to restrict exposures should continue. Although the manufacture of PCBs for commercial use has been suspended in several countries, electrical workers continue to be exposed to them through the maintenance and decommissioning of old equipment. The judgement based exposure estimates in our study are not sufficient to establish a safe level of exposure to PCBs, so measures to limit exposures to the lowest possible level would be prudent until additional information can be generated. Medical screening and surveillance of workers with a history of dermal exposure might also be warranted. Future epidemiological research with improvements in exposure measurement and detailed examination of other cancers would facilitate risk assessment.

This research was supported by contract RP-2964-05 from the Electric Power Research Institute, Palo Alto, California, USA. Electric Power Research Institute, Palo Alto, California, USA.
We also acknowledge the contributions of Dr Michael Flynn, Dr Lori Todd, Kevin Chen, Gary Mihlan, and Dr Lucy Peipins, colleagues and research assistants at the University of North Carolina; Dr Hans Kromhout at Wageningen Agricultural University, Wageningen, The Netherlands; computer programmers Richard Howard, Dr Robert Kleckner, and Joy Wood; Dr Margaret Pennybacker of Battelle-Survey Research Associates; Judith Rayner of Westat, and William West. Also, we are grateful for the time and expertise generously provided by manageme management, labour representatives, and workers at Carolina Power and Light Company, PECO Energy Company, Pacific Gas and Electric, Virginia Power Company, and the Tennessee exposure and many other aspects of the study. 
1 International Agency for Research on Cancer. IARC monographs on the evaluation of carcinogenic risks to humans. Polychlorinated biphenyls and polybrominated biphenyls. Vol 18. Lyon: IARC, 1978.

2 Kimbrough RD. Human health effects of polychlorinated biphenyls (PCBs) and polybrominated biphenyls (PBBs). Ann Rev Pharmacol Toxicol 1987;27:87-111.

3 Smith A, Brown D. Polychlorinated biphenyls in the workplace. In: Said SW, ed. PCBs and the environment. Boca Raton, FL: CRC Press, 1986:63-82.

4 National Institute of Occupational Safety and Health. Occupational exposure to polychlorinated biphenyls: criteria for a rec-
ommended standard. Cincinnati: NIOSH, US Dept of Health, Education, and Welfare, Public Health Service,

5 Silberhorn EM, Giauert HP, et al. Carcinogenicity of polyalongenated biphenyls: PCBs and PBBs. Crit Rev Toxicol 1990;20:439-96.

6 Drinker CK, Warren MF, Bennett GA. The problem of possible systemic effects from certain chlorinated hydrocarbons. F Ind Hyg Toxicol 1937;19:283-311.

7 Schwartz L. Dermatitis from synthetic resins and waxes. $\mathrm{Am}$ f Public Health 1936;26:586-92.

8 International Agency for Research on Cancer IARC monographs on the evaluation of carcinogenic risks to humans. Overgraphs on the evaluation of carcinogenic risks to humans. Over-
all evaluation of carcinogenicity: an updating of IARC all evaluation of carcinogenicity: an updating of $I A R C$
monographs volumes 1 to 42, suppl 7. Lyon: IARC, 1987.

monographs volumes 1 to 42, suppl 7. Lyon: IARC, 1987 .
9 Landrigan PJ. General population exposure to halogenated biphenyls. In: Kimbrough RD, ed. Halogenated biphenyls, terphenyls, napthalenes, dienzodioxines, and related products. Amsterdam: Elsevier-North Holland, 1989:257.

10 Nicholson WJ. Review of human health effects and carcinogenic risk potential of PCBs. Special Panel on the Occupational Risk of Mortality from Exposure to PCBs. New York: Division of Environmental and Occupational Medicine, Mt Sinai School of Medicine, 1987.

11 Lees PSJ, Corn M, Breysse PN. Evidence of dermal absorption as the major route of body entry during exposure of tion as the major route of body entry during exposure of
transformer maintenance and repairmen to PCBs. Am Ind transformer maintenance and

12 Smith AB, Schloemer J, Lowry LK, Smallwood AW, Ligo $\mathrm{RN}$, Tanaka $S$, et al. Metabolic and health consequences of occupational exposure to polychlorinated biphenyls. $\mathrm{Br} F$ Ind Med 1982;39:361-9.

13 Maroni M, Colombi A, Cantoni S, Ferioli E, Foa V. Occupational exposure to polychlorinated biphenyls in electrical
workers. I Environmental and blood polychlorinated biphenyl concentrations. Br f Ind Med 1981;38:49-54.

14 Bertazzi PA, Riboldi L, Pasatori A, et al. Cancer mortality of capacitor manufacturing workers. Am f Ind Med 1987;11: capacitor

15 Tironi A, Pesatori AC, Consonni D, Zocchetti C, Bertazzi PA. Mortality of capacitor manufacturing workers exposed to PCBs [abstract]. Epidemiology 1995;6(suppl):S1 12 .

16 Brown DP. Mortality of workers exposed to polychlorinated biphenyls--An update. Arch Environ Health 1987;42:333 9.

17 Greenland S, Salvan A, Wegman DH, Hallock MF, Smith TJ. A case-control study of cancer mortality at a transformer-assembly facility. Int Arch Occup Environ Health 1994;66:49-54.

18 Liss G. Mortality and cancer morbidity among transformer manufacturing workers, Ferranti-Packard Transformers Ltd, St Catherines. Health Studies Service, Policy and Regulations Catherines. Health Studies Service, Policy and Regulations
Branch. Toronto, Ontario: Ontario Ministry of Labor, 1989.

19 Sinks T, Steele G, Smith AB, et al. Mortality among workers exposed to polychlorinated biphenyls. Am $\mathcal{f}$ Epidemiol 1992;136:389-.98.

20 Yassi A, Tate R, Fish D. Cancer mortality in workers employed at a transformer manufacturing plant. Am $\mathcal{F}$ Ind Med 1994;25:425-37.

21 Gustavsson P, Hogstedt C, Rappe C. Short-term mortality and cancer incidence in capacitor manufacturing workers exposed to polychlorinated biphenyls (PCBs). Am F Ind Med 1986;10:341-4.

22 Bahn AK, Rosenwaike I, Grover P, et al. Melanoma after exposure to PCBs. N Engl f Med 1976;295:450.
23 Savitz DA, Loomis DP. Magnetic field exposure in relation to leukemia and brain cancer mortality among electric utility workers Am ₹ Epidemiol 1995;141:123-34.

24 Loomis DP, Peipins LA, Browning SR, Howard RL, Savitz $\mathrm{DA}$, Kromhout $\mathrm{H}$. Classification and organization of work history data in industry-wide studies: an application to the electric power industry. Am F Ind Med 1994;26:413-25.

25 US Health Care Financing Administration. Commission on Professional and Hospital Activities, international classification of diseases, ninth revision, clinical modification, 2 nd ed. Washington, DC: US GPO, 1980. (DHHS Publ No (PHS) $80-1260)$

26 Browning SR. Polychlorinated biphenyl exposure and cancer mortality among electric utility workers [dissertation]. Chapel Hill, NC: University of North Carolina, 1994

27 Kauppinen T, Partanen T. Use of plant- and period-specific job-exposure matrices in studies on occupational cancer. Scand 7 Work Environ Health 1988;14:161-7.

28 Kromhout H, Loomis DP, Mihlan GJ, et al. Assessment and grouping of magnetic field exposure in five electric utility companies. Scand f Work Environ Health 1995;21:43 50.

29 Steenland K, Beaumont J, Spaeth S, it al. New developments in the life table analysis system of the National Institute for Occupational Safety and Health. $\mathcal{F}$ Occup Med 1990;32:1091-8

30 Frome EL, Checkoway H. Use of Poisson regression models in estimating incidence rates and ratios. $A m$ f Epidemiol 1985;121:309-23.

31 Payne CD, ed. The GLIM system, release 3.77 mamul, 2 nd id. Oxford: Royal Statistical Society, 1987.

32 Rothman KJ, Boice JD Jr. Epidemiologic analysis with a programmable calculator. Boston: Epidemiology Resources, $1982 \cdot 30-1$

33 Checkoway H, Pearce N, Hickey JLS, Dement JM. Latency analysis in occupational epidemiology: F Occup Med 1990; 45:95-100.

34 Armenian HK, Lilienfeld AM. The distribution of incubation periods of neoplastic diseases. $A m \quad 7$ Epidemiol 1974;99:92-100.

35 Salvan A, Stayner L, Steenland K, Smith R. Selecting an exposure lag period. Epidemiology 1995;6:387-91.

36 Steenland K, Stayner L. The importance of employment status in occupational cohort mortality studies. Epidemiology 1991;7:418-23.

37 Armitage $P$, Doll $R$. The age distribution of cancer and a multi-stage theory of carcinogenesis. Br. 7 Cancer 1954;8:1 12

38 Sahl JD, Crocker TT, Gordon RJ, Faeder EJ. Polychlorinated biphenyls in the blood of personnel from an electric utility. F Occup Med 1985;27:639-43.

39 Hill $\mathrm{AB}$. The environment and disease: association or causation? Proc R Soc Med 1965;58:295--300.

40 Wolff $M$. Occupational exposures to polychlorinated biphenyls (PCBs). Environ Health Perspect 1985;60:133 8.

41 Kromhout H, Ostendorp Y, Heederik D, Boleij JSM. Agreement between qualitative exposure estimates and quantit:tive exposure estimates. Am F Ind Med 1987;12:551-62

42 Flynn MR, West S, Kaune WT, Savitz DA, Chen CC Loomis DP. Validation of expert judgement in assessing occupational exposure to magnetic fields in the utility industry. Appl Occup Environ Hyg 1991;6:141-5.

43 Fenske RA. Dermal exposure assessment techniques. Ann Occup Hyg 1993;37:687-706.

44 Rockley PF. Trieff N, Wagner RF. Tyring SK. Non-sunlight risk factors for malignant melanoma Part I: chemical agents, physical conditions, and occupation. Int 7 Dermatol 1994;33:398-406.

45 Gallagher RP, Elwood JM, Threfall WJ, Spinelli JJ, Fincham $S$, Hill GB. Socioeconomic status, sunlight exposure, and risk of malignant melanoma: the Western Canada Melanoma Study. $₹$ Natl Cancer Inst 1987;79:647- 52.

46 Greenland $S$. The effect of misclassification in the presence of covariates. Am $\mathcal{F}$ Epidemiol 1980;112:564 9 .

47 Percy CL, Miller BA, Gloeckler Ries LA. Effect of changes in cancer classification and the accuracy of cancer death certificates on trends in cancer mortality. Ann NY Acad $S_{c i}$ 1990;609:87- 99 . 